\title{
Alfabetização e Letramento: Um Olhar de Professores Alfabetizadores
}

\author{
Andreia Julio Rocha" \\ Otília Maria Alves da Nobrega Alberto Dantas** \\ Aldileia da Silva Souza***
}

\section{Resumo}

Este artigo investiga o processo de alfabetização e letramento numa instituição de ensino da região administrativa de Roraima. Teve como objetivo analisar as concepções de professoras acerca da alfabetização e letramento A metodologia aplicada foi pautada numa abordagem qualitativa tendo em vista a análise dos discursos extraídos das entrevistas aplicadas aos professores pesquisados. A pesquisa foi desenvolvida com três docentes que atuavam em turmas dos anos iniciais do Ensino Fundamental. Os resultados e conclusões apontam que o professor, tendo liberdade de cátedra, pode desenvolver suas práticas docentes, analisando as propostas metodológicas pré-determinadas que por vezes podem não atender as nuances que circundam o processo de ensino e aprendizagem, sobretudo no que diz respeito à alfabetização e ao letramento.

Palavras-chaves: Ensino; Alfabetização; Letramento; Professor alfabetizador; Prática docente

\section{Introdução}

* E-mail: andreiajuliomatema@gmail.com

** Professora Associada da Universidade de Brasília/Faculdade de Educação. Possui graduação em Pedagogia, mestrado e doutorado em Educação pela Universidade Federal do Rio Grande do Norte e PHD em Educação pela Universidade de Brasília sob a supervisão de Ilma Passos de Alencastro Veiga. Professora Permanente dos PPGE da Faculdade de Educação da Universidade de Brasília. Desenvolve estudos (pesquisa, ensino e extensão) na área de Educação, pesquisando: formação de professores, Pedagogia; Didática, construção do conhecimento, prática docente e saberes docentes. No âmbito da gestão atuou como Coordenadora do Curso de Pedagogia e Chefe do Departamento de Métodos e Técnicas da FE/UNB. Pesquisadora e líder do Grupo de Estudos e Pesquisa Profissão Docentes: formação, saberes e práticas - Geppesp. Membro do Comitê de Ética na Pesquisa - CEP/UnB. E-mail: otiliadantas@ gmail.com

**** E-mail: aldileiasilva.rr@hotmail.com

Data de submissão: ago. 2021 - Data de aceite: out. 2021 http://dx.doi.org/10.5335/rdes.v17i3.11377 
A Lei de Diretrizes e Bases da Educação Nacional (LDBEN) no 9.394/96, estabelece como um de seus princípios: "liberdade de aprender, ensinar, pesquisar e divulgar a cultura, o pensamento, a arte e o saber" (BRASIL, 2006). Na Constituição Brasileira os direitos de aprendizagem são garantidos a todos, bem como na educação básica, como prevê a Lei 9.394/1996 ao estabelecer as diretrizes e bases da educação nacional que assegura a formação comum, formando cidadãos críticos e formadores de opinião.

Norteados por essas perspectivas, compete ao alfabetizador, como afirma Morais (2012, p.181): "ensinar de forma cuidadosa e explícita o sistema de escrita alfabética (SEA) [...], como uma medida urgente para reinventarmos as metodologias de alfabetização que usamos em nosso país" e assim, promover e auxiliar o desenvolvimento do cidadão. De acordo com Bortoni et al, (2010), o ato da leitura vai além de decifrar códigos linguísticos, e sim, compreendê-los de maneira que eles possuam significado e contexto. Neste sentido, cabe à escola proporcionar um ambiente de integração entre aluno, leitura e contexto para formar leitores críticos capazes de interpretar o mundo ao seu redor.

Assim sendo, o estudo visa analisar as concepções de professoras acerca da alfabetização e letramento.

\section{Fundamentação Teórica}

O contexto educacional brasileiro vem sofrendo transformações e mudanças. Esse olhar já é demonstrado em documentos como a Base Nacional Comum Curricular (BNCC) (BRASIL, 2017) que desde sua apresentação elenca ser um documento com altas expectativas para ensino, isso para que se cumpra o compromisso de considerar a participação de todos os atores envolvidos neste processo de transformação (MEC, redes de ensino, escolas e educadores).

A alfabetização e letramento possuem papel relevante no contexto educacional, promovendo e facilitando o processo de ensino-aprendizagem como um todo em prol da transformação e da inserção do sujeito em prol das transformações presentes no social e cultural da escola, como destaca Mortatti (2010, p. 329):

A alfabetização escolar - entendida como processo de ensino e aprendizagem da leitura e escrita em língua materna, na fase inicial de escolarização de crianças - é um processo complexo e multifacetado que envolve ações especificamente humanas e, portanto, políticas, caracterizando-se como dever do Estado e direito constitucional do cidadão. Em sociedades letradas contemporâneas, essa relação tanto impõe a necessidade de inserção/inclusão dos não alfabetizados no mundo público da cultura escrita e nas instâncias públicas de uso da linguagem, quanto demanda a formulação de meios e modos mais eficientes e eficazes para implementar ações, visando concretizar essa inserção/inclusão, a serviço de determinadas urgências políticas, sociais e educacionais 
Ao garantir oportunidades em diferentes espaços-tempo, os processos de alfabetização e letramento tendem levar o aprendiz a apropriação da leitura e escrita de modo integral, contextualizado e inclusivo. Sobre isto,

[...] os conteúdos dos diversos componentes curriculares [...], ao descortinarem às crianças o conhecimento do mundo por meio de novos olhares, lhes oferecem oportunidades de exercitar a leitura e a escrita de um modo mais significativo (BRASIL, 2017, p. 59).

Essa compreensão de que indivíduos letrados terão maior oportunidades de participar como atores ativos e pensantes na organização social e com isso transformando a sociedade como um todo, tornando-o capaz de compreender, criticar, interpretar e construir conhecimentos. Contrapondo a ideia apresentada, Morais (2012, p. 27) destaca que:

[...] os métodos tradicionais de alfabetização que conhecemos, apesar das diferenças que apresentam, tem uma única e comum teoria de conhecimento subjacente: a visão empirista/associacionista de aprendizagem. Segundo tal perspectiva, o aprendiz é uma tábula rasa e adquire novos conhecimentos (sobre o alfabeto) recebendo informações prontas do exterior (explicação sobre letras e sons) que, através da repetição do gesto gráfico (cópia) e da memorização (das tais relações entre letra e som), passariam a ser suas.

Convém ressaltar que alfabetizar, até a década de 1980, exigia-se do docente, domínio do método tradicional, onde o estudante repetia exaustivamente as letras, as sílabas, em um processo de acumulação, até chegar a ser capaz de ler um texto. Nesse cenário, cabia ao professor oferecer-lhe os caminhos, por meio de uma prática unilateral, cuja preocupação era seguir, rigidamente, um método. Após essa década, com os estudos de Ferreiro e Teberosky (1999) sobre a Psicogênese da Língua Escrita, houve uma mudança de foco, do como se ensina para o como se aprende, tornando o aprendiz ativo e capaz de refletir sobre a escrita alfabética. Com isto, ao professor competia oferecer ao aprendiz os meios e as intervenções necessárias tornando possível a apropriação do sistema.

Diversos autores e pesquisadores abordam os conceitos de alfabetização e letramento. Segundo Soares (2010), o termo letramento apresenta duas dimensões: uma individual e outra social. $\mathrm{Na}$ individual o letramento tem âmbito pessoal e na social se configura como fenômeno cultural. Para ser possível a compreensão dessas dimensões é fundamental considerar a leitura e a escrita.

$O$ conceito de alfabetização não se restringe ao processo de codificação/ decodificação, pois as práticas sociais de leitura são necessárias para que o indivíduo possa fazer uso dos diversos gêneros textuais. Assim, Soares (2003, p. 47) conceitua a alfabetização como “[...] a ação de ensinar a ler e escrever". No entanto, o indivíduo desde cedo passa pelo processo de letramento antes, durante e após ser alfabetizado, ao realizar 
leituras de imagens, rótulos, emoções, dentre outros, presente em sua realidade. De acordo com Rojo (2012, p. 35), “[..] o contato com o mundo letrado acontece muito antes das letras e vai além dela".

Assim, conforme Morais (2012), alfabetizar, hoje, supõe um trabalho sistemático e intencional com o Sistema de Escrita Alfabético (SEA), não descartando as possibilidades de trabalho com a consciência fonológica. Contudo, o letramento constitui-se em amplo processo, tanto dentro como fora do ambiente escolar.

A partir destes olhares é possível observar que ao professor compete disponibilizar, aos estudantes, esse leque de possibilidades advindas de sua realidade ou cotidiano, que nada tem se diferencia das antigas cartilhas. Ao trabalhar esses diferentes gêneros em sala de aula, tanto para ler, como para escrever, o estudante é preparado para protagonizar sua própria aprendizagem apropriando-se de habilidades de leitura e escrita, essenciais para o seu desenvolvimento e participação ativa na sociedade.

Freire (2002, p. 112) reforça a ideia de que "[...] ser alfabetizado é tornar-se capaz de usar a leitura e a escrita como um meio de tomar consciência da realidade e transformá-la”. Dessa forma, a alfabetização é vista de forma mais ampla, para além dos códigos escritos, pois é na prática discursiva que é proporcionada a leitura crítica de seu contexto, favorecendo as práticas sociais, no qual irá melhorar a qualidade de vida dos indivíduos diante das mudanças sociais que ocorrem na contemporaneidade. Afirma, ainda, que o ser humano ao longo da história, teve a necessidade de fazer primeiro a leitura de mundo e depois a de palavras. Muito antes dos códigos linguísticos ele já realizava a leitura ao seu redor.

Para o processo de alfabetização é fundamental que $o$ aprendiz se aproprie dos diferentes gêneros textuais. Sobre isto destacam Maciel e Lúcio (2009, p. 17)

Não é raro observamos professores que consideram necessária a interação com diferentes gêneros textuais na formação do leitor/ escritor competente, mas que, na sala de aula, recorrem basicamente a pseudotextos no trabalho de alfabetização [...] muitos professores ainda acreditam que somente após o processo da alfabetização é que deve ser iniciado o processo de letramento, ou seja, que para se tornar letrado, é preciso, primeiramente, adquirir a tecnologia da escrita.

De acordo com Soares, uma pessoa letrada pode não ser alfabetizada, mas é capaz de fazer uso da leitura de mundo quando identifica o valor monetário, faz cálculos, entre outros). Ela (SOARES, 2010, p. 10) destaca ainda que:

Dissociar alfabetização e letramento é um equívoco porque, no quadro das atuais concepções psicológicas, linguísticas e psicolinguísticas de leitura e escrita, a entrada da criança (e também do adulto analfabeto) no mundo da escrita ocorre simultaneamente por esses dois processos: pela aquisição do sistema convencional de 
escrita - a alfabetização - e pelo desenvolvimento de habilidades de uso desse sistema em atividades de leitura e escrita, nas práticas sociais que envolvem a língua escrita - o letramento. Não são processos independentes, mas interdependentes, e indissociáveis: a alfabetização desenvolve se no contexto de e por meio de práticas sociais de leitura e de escrita, isto é, através de atividades de letramento, e este, por sua vez, só se pode desenvolver no contexto da e por meio da aprendizagem das relações fonema-grafema, isto é, em dependência da alfabetização.

A afirmação de Soares nos encaminha a percepção de que a alfabetização envolve dois processos que seriam a aquisição do sistema da escrita como ler e escrever por meio de uma codificação e a decodificação.

Os estudos de letramento e alfabetização estão intrinsecamente correlacionados, mas ao mesmo tempo distintos. Diante dessa ideia podemos enfatizar que alfabetizar letrando não é tarefa fácil, cabe ao alfabetizador direcionar o aluno a ler e escrever, envolvendo as práticas sociais do seu contexto e os conhecimentos do seu cotidiano criando situações significativas. Morais e Albuquerque (2006, p. 69) nos recomenda que:

[...] democratizar o acesso ao mundo letrado não significa encher a sala de aula de recortes de jornais, rótulos, embalagens, cartazes publicitários e colocar livros numa estante. Pressupõe, isto sim, que o aprendiz possa vivenciar, no cotidiano escolar, situações em que textos são lidos e escritos porque atendem a uma determinada finalidade.
Desse modo, o alfabetizador planeja, de acordo com a necessidade do aprendiz, entendendo o contexto e considerando o processo de aprendizagem, oportunizando a possibilidade de pensar, refletir e aprender de forma prazerosa e significativa. $\mathrm{O}$ alfabetizador necessita, portanto, estimular o desenvolvimento de habilidades e reflexões com relação à língua escrita numa prática mediadora e comprometida, em prol do da melhoria da qualidade do ensino e o sucesso da aprendizagem dos alunos.

\section{Metodologia}

A presente pesquisa ocorreu em 2018, por ocasião do desenvolvimento de estudos oportunizados pela "Escola de Altos Estudos", um programa desenvolvido pela UFPE em parceria com a UnB. Deste modo, o artigo visa analisar o processo e a relação entre alfabetização e letramento para professores alfabetizadores. Numa abordagem qualitativa intencionamos, mesmo que de forma inicial, coletar informações, significados e conceitos, de modo a promover um confronto entre os dados empíricos coletados em campo, e o conhecimento científico expresso pelos teóricos que tratam da temática proposta.

Assim, foi utilizada a pesquisa descritiva que segundo Prodanov e Freitas (2013), proporciona ao pesquisador descrever e observar fatores positivos e negativos, sem intervir no que foi 
observado e, a partir daí, reconhecer as características de determinado grupo, tendo em vista a observação, o registro e a ordenação dos dados necessários à compreensão do problema.

Os pesquisados foram 3 (três) professores de uma instituição pública de Roraima. Consideramos como critério de participação, atuar nos anos iniciais (turmas de alfabetização) do Ensino Fundamental. Segundo Prodanov e Freitas (2013), um grupo pequeno de sujeitos pesquisados é perfeitamente possível considerando sua representatividade na sociedade.

Como procedimento de estudo, foi realizada a pesquisa de campo, cujo instrumento utilizado para a coleta de dados foi uma entrevista estruturada, composta de um total de (5) cinco questões visando coletar as informações e/ ou conhecimentos necessários para a conclusão da pesquisa.

Para compreender o processo e a relação entre alfabetização e letramento foi realizada uma entrevista presencial, gravadas e transcritas, que ao realizar a análise das transcrições, decidimos por dividir as informações em categorias, quais sejam: Perfil dos professores; Diferença entre Alfabetização e Letramento e por fim, Prática docente.

Para uma compreensão da primeira categoria que denominamos Perfil do Egresso, definimos duas subcategorias: formação docente e tempo de experiência em alfabetização. Essas informações subsidiaram a análise das respostas dadas pelas professoras pesquisadas, considerando que a formação e o tempo de experiência denotasse algum contato com diferentes métodos de alfabetização, seja silábico ou fonético. A pergunta realizada neste momento foi sobre a formação e o tempo de atuação em sala de aula.

Para a segunda categoria Diferença entre alfabetização e letramento, definimos duas subcategorias: compreensão de letramento e compreensão sobre alfabetização. Com essas subcategorias, intencionamos, neste momento, ter subsídios que denotassem o olhar e compreensão sobre esses dois conceitos, o que acreditávamos nos encaminharia a compreensão sobre a prática docente. A pergunta realizada para este segundo momento foi: qual a sua compreensão entre Alfabetização e Letramento?

$\mathrm{Na}$ terceira categoria, que dista sobre a prática docente, acreditávamos identificar divergências das afirmações realizadas sobre as diferenciações solicitadas na segunda categoria. Deste modo, para atingir o objetivo, dividimos a análise em subcategorias para identificar o foco de ensino dos professores, seja na aprendizagem ou no ensino. Intencionávamos com isso, justificar o uso de metodologias divergentes da descrita pelos teóricos abordados no texto.

O quadro 01 apresenta a síntese das respostas das professoras pesquisadas. 
Quadro 1 - Síntese das respostas das professoras pesquisadas

\begin{tabular}{|c|c|c|}
\hline CATEGORIAS & SUBCATEGORIAS & EXCDRTOS \\
\hline \multirow{2}{*}{$\begin{array}{l}\text { Perfil dos } \\
\text { professores }\end{array}$} & Formação & Todos licenciados em Pedagogia. \\
\hline & $\begin{array}{l}\text { Tempo de } \\
\text { experiência }\end{array}$ & $\begin{array}{l}2 \text { (duas) professoras com } 10 \text { anos de experiências e } 1 \underline{\text { (uma) }} \\
\text { professora com experiência de } 19 \text { anos em alfabetização. }\end{array}$ \\
\hline \multirow{4}{*}{$\begin{array}{l}\text { Alfabetização e } \\
\text { Letramento }\end{array}$} & \multirow{2}{*}{$\begin{array}{l}\text { Compreensão de } \\
\text { Letramento }\end{array}$} & $\begin{array}{l}\text { Letramento é quando tem certo conhecimento por algo, mas não } \\
\text { codifica (é letrado), conhece símbolo, ex; Coca Cola, sabe o que } \\
\text { é, porém não sabe codificar os códigos (fazer a leitura, c com o, c } \\
\text { com a). (P1) }\end{array}$ \\
\hline & & $\begin{array}{l}\text { Letramento é quando utiliza a palavra ou texto onde o aluno } \\
\text { consiga ler e internretar (P2) }\end{array}$ \\
\hline & \multirow{2}{*}{$\begin{array}{l}\text { Compreensão de } \\
\text { Alfabetização }\end{array}$} & $\begin{array}{l}\text { A alfabetização faz a junção com o conhecimento prévio que se } \\
\text { possui com as informações passadas, como em conhecer as letras } \\
\text { as silabas e sua junção para formar palavras, sendo um conjunto o } \\
\text { letramento e alfahetização (P1) }\end{array}$ \\
\hline & & $\begin{array}{l}\text { Alfabetização é quando utiliza um método de regras e códigos } \\
\text { com aluno (P1). }\end{array}$ \\
\hline \multirow{5}{*}{ Prática Docente } & \multirow{2}{*}{$\begin{array}{l}\text { Foco em como } \\
\text { ensinar }\end{array}$} & $\begin{array}{l}\text { Trabalho com várias atividades de alfabetização, através de } \\
\text { ditados, jogos pedagógicos (as vezes confeccionados por mim), } \\
\text { alfabeto móvel (onde o aluno faz a junção da consoante com a } \\
\text { vogal formando a sílaba e depois a palavra) e na escrita com a } \\
\text { caligrafia ( P2) }\end{array}$ \\
\hline & & $\begin{array}{l}\text { Hoje, já vem apostilado, tudo pronto, assim como o programa que } \\
\text { é trabalhado na nossa rede municipal, onde já vem tudo pré- } \\
\text { determinado em que eu não posso aproveitar algo de fora e partir } \\
\text { dele para ir contextualizando, porque já tenho algo já estabelecido } \\
\text { (um cronograma para seguir) e não posso mudar (P1) }\end{array}$ \\
\hline & \multirow{3}{*}{$\begin{array}{l}\text { Foco na } \\
\text { aprendizagem }\end{array}$} & $\begin{array}{l}\text { Na minha prática eles são trabalhados em conjunto tanto } \\
\text { letramento como alfabetização, juntando e organizando para que a } \\
\text { criança consiga sistematizar e relacionar seu conhecimento do } \\
\text { cotidiano para facilitar o processo de codificação, alfabetização e } \\
\text { letramento. (P1). }\end{array}$ \\
\hline & & $\begin{array}{l}\text { Trabalho através de interpretação de imagens, para estimular a } \\
\text { oralidade da criança. Depois inserir leituras com imagens, } \\
\text { interpretações de texto, deverá ser usado bastante o lúdico(P3) }\end{array}$ \\
\hline & & $\begin{array}{l}\text { A formação continuada nesta área [...], quando aconteciam eram } \\
\text { de grande importância para a prática profissional. (P3). }\end{array}$ \\
\hline
\end{tabular}

Fonte: das autoras. 
Ressaltamos, no entanto, que foi elencada apenas respostas que se adequaram às categorias estabelecidas.

\section{Análise dos resultados}

Sobre a primeira categoria ficou evidenciado que as professoras pesquisadas apresentaram uma vasta experiência docente entre 9 e 10 anos. Elas possuem formação em Pedagogia, o que a consideramos positiva para o trabalho que desenvolvem com os processos de ensino e aprendizagem no âmbito da alfabetização e letramento.

Sobre a segunda categoria, em que foi solicitada uma definição sobre letramento e alfabetização, ficou evidenciado a concepção de aprendizagem da língua de forma variada, num primeiro momento compreende-se o processo de alfabetização como uma codificação onde são realizadas a junção de sílabas e letras como destaca P1: "conhece símbolo, ex; Coca Cola, sabe o que é, porém não sabe codificar os códigos (fazer a leitura, c com o, c com a)", o que nos encaminha ao método silábico.

Ainda sobre a segunda categoria, o professor P2 respondeu que: "Letramento é quando utiliza a palavra ou texto onde o aluno consiga ler e interpretar". Assim, se considerarmos a definição que é corroborada por Soares (2010, p. 10) quando afirma que
[...] leitura e escrita, nas práticas sociais envolvem a língua escrita - o letramento. Não são processos independentes, mas interdependentes, e indissociáveis: a alfabetização desenvolve se no contexto de e por meio de práticas sociais de leitura e de escrita, isto é, através de atividades de letramento, e este, por sua vez, só se pode desenvolver no contexto da e por meio da aprendizagem das relações fonema-grafema, isto é, em dependência da alfabetização.

Observamos ainda que os docentes participantes da pesquisa, apresentam níveis diferentes de conhecimento em relação à alfabetização e letramento. Entretanto, sinalizam que em sua prática trabalham a interação a partir dos conhecimentos prévios dos alunos, para alcançar os objetivos, almejando sempre a aprendizagem, o que consideramos positivo por entendermos que o alfabetizador deve prezar pela qualidade do ensino, assim como a aprendizagem.

$\mathrm{Na}$ terceira categoria selecionamos os excertos sobre o que era imprescindível para que o aluno se apropriasse da alfabetização e letramento. As respostas nos encaminharam a analisar o foco desses profissionais em relação ao processo de ensino. Podemos identificar que as professoras ora se colocam preocupadas em como ensinar. Segundo P2, "[...] trabalho com várias atividades de alfabetização, através de ditados, jogos pedagógicos (às vezes confeccionados por mim), alfabeto móvel (onde o aluno faz a junção da consoante com a vogal formando a sílaba e depois a palavra) e na escrita com a cali- 
grafia". Também se colocam preocupadas com a aprendizagem, como indica P1 “[...] na minha prática eles são trabalhados em conjunto tanto letramento como alfabetização, juntando e organizando para que a criança consiga sistematizar e relacionar seu conhecimento do cotidiano para facilitar o processo de codificação, alfabetização e letramento [...]". O discurso evidencia uma certa compreensão de que a alfabetização e o letramento são conceitos indissociáveis. Nesta mesma categoria localizamos P3 destacando que a formação dos professores, “[...] formação continuada nesta área [...], quando acontecia, era de grande importância para a prática profissional". Essa ideia, encontrada em Jesus e Razera (2021) quando criticam a racionalidade não como a técnica pautada numa concepção do professor como mero executor de tarefas, mas como um articulador do pensar e agir numa perspectiva reflexiva. $\mathrm{O}$ discurso ainda denota uma dependência em relação a utilização de métodos pré-estabelecidos e sistematizados para o trabalho docente.

Vale ressaltar que no ano de 2013, foi implantado pela gestão municipal um programa de ensino, que tinha por objetivo o desenvolvimento das escolas do município a partir de "conteúdos sistematizados organizados em uma sequência lógica" (IAB EM PAUTA, 2013, p. 2). Este programa também contava com acompanhamentos e assessoria desde gestores, coordenadores, professores até outros profissionais da educação, além de disponibilizar cursos de capacitação para todos os funcionários, com o intuito de auxiliar nas atividades propostas pelo programa.

O material utilizado passou por avaliação técnica do Ministério da Educação e pela Secretaria Municipal de Educação de Boa Vista. A metodologia apresentada neste suporte didático consistia em um conjunto de livros e cadernos de questões que eram utilizados pelos estudantes, tanto no ambiente escolar, quanto fora deste. Ademais, para que os professores pudessem se apropriar e aplicar prontamente o programa de alfabetização foi oferecido um guia orientador.

Outro destaque é que o programa recebe constante monitoramento por técnicos da Secretaria Municipal de Educação Estes profissionais observam as demandas apresentadas e, através de reuniões mensais com os gestores das unidades de ensino, propunham a trabalhar as problemáticas apresentadas. Além disso, são realizadas reuniões de planejamento entre os professores. Como destaca Chartier (2007, p. 160):

É o professor que conduz a turma, organiza as atividades, ajuda os alunos e julga seus resultados. Isso significa que ele não pode apenas ser aquele que executa um programa, pois o sucesso de seus depende da margem de iniciativa em que ele cria sua maneira de dar aula. O professor não tem de lidar com "sujeitos cognitivos em desen- 
volvimento", mas com um grupo de crianças, cada uma com sua história singular.

Pela prática docente, diretamente ligada à formação, o professor pesquisador constrói sua autonomia profissional vinculada à formação continuada (TIBALLI, 2001). Assim, trabalhada em diferentes olhares e metodologias diferenciadas, oportuniza o exercício autônomo e emancipatório levando-os a compreenderem o seu papel social.

Dessa forma, concordamos com Soares (2010) ao afirmar que o envolvimento deste profissional com as questões do cotidiano escolar é inevitável e, ao mesmo tempo, imprescindível para o desenvolvimento dos processos de alfabetização e letramento. Portanto, utilizando do conhecimento próprio da sua função, acreditamos que o professor conseguirá articular as dimensões pedagógicas em prol do alcance dos objetivos traçados no planejamento.

\section{Considerações finais}

Ao investigarmos as práticas pedagógicas de alfabetização e letramento das três professoras, observamos a forma de organização do trabalho pedagógico e atuação, identificando as ações pedagógicas desenvolvidas em sala de aula.

De modo geral, pode-se concluir que, para cumprir a função, o papel e as atribuições pertinentes à alfabetização e letramento, o docente necessita pos- suir conhecimentos das dimensões que perpassam o seu trabalho didático-pedagógico.

Ainda considerando a pesquisa realizada, sugerimos um olhar crítico sobre o que lhe é imposto enquanto programas de alfabetização e letramento no intuito de copiar, ipsi literis, o que lhe é determinado. É preciso ter consciência de que, pela LDB, o professor tendo liberdade de cátedra, pode desenvolver suas práticas docentes, analisando as propostas metodológicas pré-determinadas que por vezes podem não atender as nuances que circundam o processo de ensino e aprendizagem, sobretudo no que diz respeito à alfabetização e ao letramento.

\section{Literacy and Lettering A Look at Pedagogical Action}

\section{ABSTRACT}

This article investigates the literacy process in a teaching institution from the administrative region of Roraima. It aims to analyze the teachers' conceptions regarding reading and writing skills and literacy. The methodology applied was based in a qualitative approach in view of the discourse analysis extracted from the applied interviews to researcher teachers. The research was developed with three teachers who worked in classes from the early years of Elementary School. The results and conclusions indicate that the teacher, having the freedom of cathedra, can develop their teaching practices, analyzing the pre- 
determined methodological proposals that may not attend the nuances surrounding the teaching and learning process, especially regarding to literacy.

Keywords: Teaching; Reading and writing skills; Literacy; Literacy teacher; Teaching practice

\section{Referências}

BRASIL. Lei de Diretrizes e Bases da Educação Nacional - LDBEN no ${ }^{\circ}$ 9.394, de 20 de dezembro de 1996, Dispositivos Constitucionais, Emenda Constitucional n⿳‥ 11, de 1996, Emenda Constitucional no. 14, de 1996, Lei nº. 9.424, de 24 de dezembro de 1996 e Regulamentações Pertinentes. Brasília, 2006.

BRASIL, Secretaria de Educação Fundamental. Parâmetros curriculares nacionais: língua portuguesa; v.2. - Brasília, 1997.

BRASIL. Base Nacional Comum Curricular: Ensino Médio. Diário Oficial da União: seção: 1, Brasília, DF, p. 146, 21 dez. 2017. Portaria n. 1.570/2017.

BORTONI-RICARDO, S. M.; MACHADO, V. R.; CASTANHEIRA, S. F. Matrizes de referência para a formação e o trabalho do professor como agente de letramento. In: BORTONI-RICARDO, S. M.; MACHADO, V. R.; CASTANHEIRA, S. F. Formação do professor como agente letrador. São Paulo: Contexto, 2010.

CHARTIER, A. A leitura e sua aquisição: modelos de ensino, modelos de aprendizagem. Tradução BRANDÃO, Ruth Silviano. In CHARTIER, Anne-Marie. In: Práticas de leitura e escrita: história e atualidade. Belo Horizonte: Ceale/Autêntica, 2007.

JESUS, A. M. P. e RAZERA, J. C. C. , Paulo Freire em artigos sobre formação de professores na área brasileira de educação e Ciências. Disponível em: <https://www. bing.com/search?q=artigo+sobre+frmação+docente\&cvid=b3afc7c5b0ba4c08ac18a359d6d46bfb\&aqs=edge..69i57j0.5769j0j1\&pgl$\mathrm{t}=43 \& \mathrm{FORM}=\mathrm{ANNAB} 1 \& \mathrm{PC}=\mathrm{U} 531>$. Acesso em: 06 de Jun. de 2021.

FERREIRO, E.; TEBEROSKY, A. Introdução. In: FERREIRO, E.; TEBEROSKY, A. Psicogênese da língua escrita. Porto Alegre: Artes Médicas Sul, 1999, p. 17-35.

FREIRE, P. Educação como prática de liberdade. Rio de Janeiro: Paz e Terra, 2002.

IAB EM PAUTA. Boa Vista começa a grande virada na educação: alguns professores notam aceleração na aprendizagem já no primeiro semestre de adoção dos programas do IAB. Boa Vista - ANO IV - 2013.

MACIEL, F. I. P.; LÚCIO, I. S. Os conceitos de alfabetização e letramento e os desafios da articulação entre teoria e prática. In: CASTANHEIRA, M. L.; MACIEL, F. I. P.; MARTINS, R. M. F. Alfabetização e Letramento na sala de aula. 2. ed. Belo Horizonte: Ceale/ Autêntica, 2009.

MORAIS, A.G. de. Sistema de escrita alfabética. São Paulo: Editora Melhoramentos, 2012.

MORAIS, A.G. e ALBUQUERQUE, E. B. C. Alfabetização e letramento: O que são? Como se relacionam? Como "alfabetizar letrando"? In: ALBUQUERQUE, E. B. C. e LEAL, T.F. Alfabetização de Jovens e Adultos. Em uma perspectiva de letramento. 3 ed. Belo Horizonte: Autêntica, 2006.

MORTATTI, M. do R.L. Alfabetização no Brasil: conjecturas sobre as relações entre políticas públicas e seus sujeitos privados. Revista Brasileira de Educação. V. 15, n. 44 maio/agosto, 2010, p. 329-341.

PRODANOV, Cleber Cristiano; FREITAS, Ernani Cesar de. Metodologia do trabalho científico [recurso eletrônico]: métodos da pesquisa e do trabalho acadêmico. 2. ed. Novo Hamburgo: Feevale, 2013. Disponível em: https://aedmoodle.ufpa.br/pluginfile. php/291348/mod_resource/content/3/2.1-E- 
-book-Metodologia-do-Trabalho-Cientifico-2. pdf . Acesso em 06 de Jun. de 2021

SOARES, M. Letramento: um tema em três gêneros/Magda Soares. 4. ed. Belo Horizonte: Autêntica Editora, 2010.

SOARES, M. Letramento e alfabetização: as muitas facetas - Revista Brasileira de Educação - UFMG, Ano XVIII, no ${ }^{-162, ~ p . ~}$ 30, maio 2003.

TIBALLI, E. F. A. Considerações pedagógicas a respeito da formação do professor reflexivo. Educativa, Goiânia, v. 4, n.2, p.241-250, jul./dez.2001.

ROJO, R. Multiletramentos na escola. São Paulo: Parábola Editorial. 2012. 